\title{
The very many faces of presenilins and the $\gamma$-secretase complex
}

\author{
Michalina Smolarkiewicz • Tomasz Skrzypczak • \\ Przemyslaw Wojtaszek
}

Received: 27 January 2013 / Accepted: 1 March 2013 /Published online: 16 March 2013

(C) The Author(s) 2013. This article is published with open access at Springerlink.com

\begin{abstract}
Presenilin is a central, catalytic component of the $\gamma$ secretase complex which conducts intramembrane cleavage of various protein substrates. Although identified and mainly studied through its role in the development of amyloid plaques in Alzheimer disease, $\gamma$-secretase has many other important functions. The complex seems to be evolutionary conserved throughout the Metazoa, but recent findings in plants and Dictyostelium discoideum as well as in archeons suggest that its evolution and functions might be much more diversified than previously expected. In this review, a selective survey of the multitude of functions of presenilins and the $\gamma$-secretase complex is presented. Following a brief overview of $\gamma$-secretase structure, assembly and maturation, three functional aspects are analyzed: (1) the role of $\gamma$-secretase in autophagy and phagocytosis; (2) involvement of the complex in signaling related to endocytosis; and (3) control of calcium fluxes by presenilins.
\end{abstract}

Keywords Presenilin · Gamma-secretase - Alzheimer disease $\cdot$ Complex assembly and maturation $\cdot$ Proteolytic activity $\cdot$ Biological functions $\cdot$ Endocytosis $\cdot$ Calcium homeostasis $\cdot$ Autophagy

\section{Introduction}

Presenilin (PS), a multiple pass transmembrane protein, forms the catalytic core of gamma-secretase - a unique transmembrane complex with proteolytic activity. PSs were

Handling Editor: David Robinson

M. Smolarkiewicz $\cdot$ T. Skrzypczak $\cdot$ P. Wojtaszek $(\bowtie)$

Department of Molecular and Cellular Biology,

Faculty of Biology, Adam Mickiewicz University,

Umultowska 89,

61-614 Poznań, Poland

e-mail: przemow@amu.edu.pl first identified by St. George-Hyslop's group in genetic screens for mutations causing early onset forms of familial Alzheimer's disease (FAD; Sherrington et al. 1995). It was later found that $\gamma$-secretase is responsible for the cleavage of Amyloid- $\beta$ (A $\beta$ ) precursor protein (APP) in a process which generates amyloid precursor protein intracellular domain (AICD) and an extracellular A $\beta$ peptide. The cleavage fragments act as versatile signaling molecules both in intra- and extracellular compartments.

$\mathrm{A} \beta$ peptides range from 37 to 49 residues, and in normal brain tissue most of them is of a 40-residues type. FADassociated mutant forms of PS on the contrary, generate A $\beta$ peptides of 42-residues type. The latter are highly amyloidogenic, and their accumulation leads to plaque formation and progressive neurodegeneration (Citron et al. 1997). Almost at the same time the newly identified PS homologue in Caenorhabditis elegans, sel-12, was reported to be involved in the Notch signaling pathway (Levitan and Greenwald 1995). This highly conserved pathway is essential for metazoan development (Del Amo et al. 1992; Tien et al. 2009; Sethi and Kang 2011). PS has been implicated in the cleavage of the Notch receptor. The released Notch Intracellular Domain (NICD) of the receptor was then shown to function in the nucleus as the transcription factor (Fortini 2002; Baulac et al. 2003; Bray 2006). Both findings gave the direction to PS research for many years, focusing it mainly on these two aspects. However, recent data indicate that PSs and the $\gamma$-secretase complex fulfill many more biological functions with some of them independent of the $\gamma$-secretase proteolytic activity. In this review, following a brief description of the components and assembly of $\gamma$-secretase complex, we will focus on its various functional aspects: its potential substrates, its role in autophagy and endomembrane trafficking, and its regulation of calcium fluxes. Other aspects of $\gamma$-secretase/presenilin functioning have recently been covered in several excellent reviews (see Dries and Yu 2008; Brou 2009; De Strooper and Annaert 2010; van Tetering and Vooijs 2011; 
Crump et al. 2011; Wolfe 2012; Beckett et al. 2012; St. GeorgeHyslop and Fraser 2012).

\section{Gamma-secretase complex: a 3D puzzle}

Gamma-secretase is a multisubunit intramembranous protein complex that handles proteolysis inside the hydrophobic environment of a lipid bilayer. Together with site 2 proteases (S2P), signal peptide peptidases (SPP) and rhomboids, it belongs to a unique group of so-called I-CLiPs (intramembrane-cleaving proteases) involved in regulated intramembrane proteolysis (RIP; Sannerud and Annaert 2009). This is an evolutionary conserved process which was shown to be required for signal transduction on the one hand (De Strooper et al. 1999; Lal and Caplan 2011), and for the degradation of transmembrane protein fragments on the other (Kopan and Ilagan 2004; Lichtenthaler et al. 2011). Gamma-secretase differs from other members of the I-CLiP family which - besides a catalytic core protein (PS) - has three other, non-catalytic subunits that are required for its activity: nicastrin (NCT), presenilin enchancer-2 (PEN-2) and anterior pharynx defective-1 (APH-1) (Rogaev et al. 1995; Sherrington et al. 1995; Francis et al. 2002; Parks and Curtis 2007). The genes coding for all subunits of the $\gamma$-secretase complex have been found in genomes of metazoans and higher plants, but are missing in fungi (Ponting et al. 2002; Lemberg 2011). There is also very intriguing evidence that $\gamma$-secretase functions in the evolutionary distinct slime mold, Dictyostelium discoideum, and in the moss, Physcomitrella patens. This might suggest that the complex activity might be far more ancient than was previously anticipated (Khandelwal et al. 2007; McMains et al. 2010). Indeed, some experimental data suggest that MCMJR1, a polytopic membrane protein from the archaeon Methanoculleus marisnigri JR1, reveals key biochemical characteristics of eukaryotic PS (Torres-Arancivia et al. 2010).

The bits and pieces

PSs are aspartyl proteases with catalytic residues localized inside the lipid bilayer on transmembrane domain 6 (TMD6) and TMD7 (Fig. 1). In most genomes studied the PS family comprises two homologous proteins: PS1 and PS2. They share ca. $67 \%$ of amino acid sequence identity, but are not redundant. In mice, knockout mutation of PS1 is lethal at early embryogenesis, while PS2 knockout shows only a mild phenotype related to pulmonary fibrosis (Herreman et al. 1999; Dries and Yu 2008). There are several motifs conserved evolutionary across many species in both amino acid sequences. The most important include: YD and GXGD motifs containing catalytic aspartyl residues or an ER-retention sequence (Kaether et al. 2004; Wolfe 2009; Fassler et al. 2011). For a very long time the exact topology of PSs was under dispute with two major models depicting PS molecules either with eight or nine transmembrane domains ( $\mathrm{Li}$ and Greenwald 1996; Kim and Schekman 2004; Spasic et al. 2006). In recent years, however, evidence gathered has established a view of PS containing nine TMDs (Fig. 1; Sato et al. 2008; Tolia et al. 2008; Li et al. 2013; Sobhanifar et al. 2010). In metazoans, PS is synthesized as a holoprotein and then it undergoes autocatalytic endoproteolysis between TMD6 and TMD7. The released amino- and carboxy-terminal fragments (NTF and CTF, respectively) are associated with conformational changes in the complex and function together as a heterodimer (Shirotani et al. 2003; Dries and Yu 2008; McCarthy et al. 2009).

In early studies, PS was thought to be the catalytic core of $\gamma$-secretase and the only element necessary for proteolysis. Yet, it was realized very quickly that additional proteins are also required for the activity of the complex (Spasic and Annaert 2008). The first one identified was nicastrin. It was found through co-immunoprecipitation studies ( $\mathrm{Yu}$ et al.

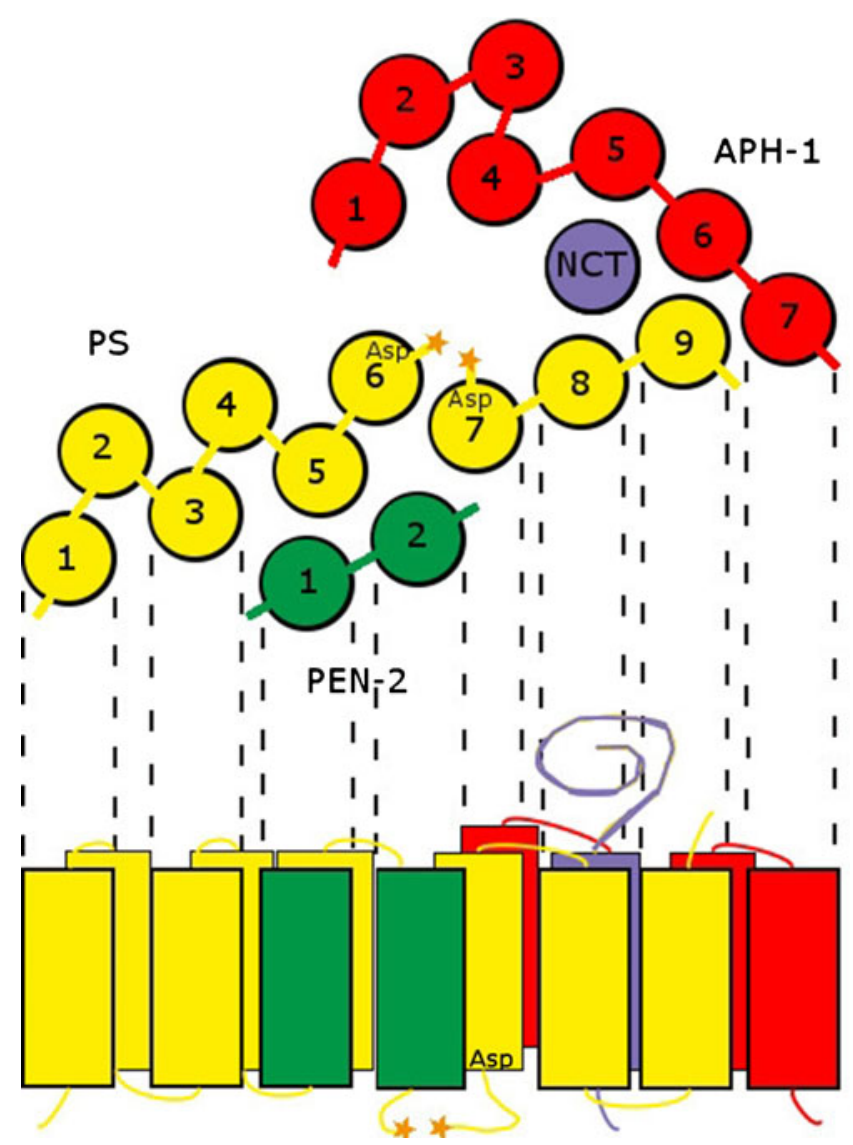

Fig. 1 The active $\gamma$-secretase complex is composed of four subunits: presenilin ( $P S$, yellow) with catalytic aspartyl residues (Asp), highly glycosylated nicastrin (NCT, violet), presenilin enhancer 2 (PEN-2, green), and anterior pharynx defective $1(A P H-1, r e d)$. In a mature complex, PS is autoendoproteolytically cleaved (stars) within a loop between TMD6 and TMD7. Both the catalytic aspartyl residues of PS are also localized within TMD6 and TMD7. Substrate binding site and active site are very close to each other. PEN-2 interacts with PS NTF. NCT/APH-1 subcomplex interacts with PS CTF 
2000) and, in parallel, in genetic studies on Notch signaling in C. elegans (Levitan et al. 2001). The protein was named after the Italian village Nicastro, reflecting the fact that Alzheimer's disease was described after studying descendants of an extended family originating from the village (Feldman et al. 1963). Nicastrin is a large protein, containing single transmembrane domain. NCT is itself not catalytically active, but instead promotes the maturation and proper trafficking of the other components of the $\gamma$ secretase complex. It is characterized by a unique DYIGS amino acid motif. Within the complex NCT acts probably as the substrate recognition and binding site (Wolfe 2009). Its immature or improperly glycosylated form is rapidly degraded by both proteasome and lysosome pathway (He et al. 2007).

Two additional members, APH-1 and PEN-2, were discovered independently during the search for Notch and/or PS interacting partners in C. elegans (Francis et al. 2002; Goutte et al. 2002). PEN-2, containing 101 amino acids, is the smallest subunit of $\gamma$-secretase complex and shares no significant domain homology with any other known protein family (Dries and Yu 2008). PEN-2 has two transmembrane domains connected with a short cytoplasmic loop. Both the $\mathrm{N}$ and $\mathrm{C}$ termini are exposed to the extracellular space (Crystal et al. 2003). A putative ER retention signal is localized within TMD1 (Fassler et al. 2010). PEN-2 is most likely involved in complex stabilization and plays an important role both in PS autoproteolysis and in the proteolytic activity of the whole complex (Bammens et al. 2011). APH-1 protein has seven transmembrane domains and acts potentially as a scaffold for complex formation (Fig. 1). It was shown to contribute to proper assembly of the complex (Gu et al. 2003). Two APH-1 homologues, APH-1a and APH-1b, have been identified in human, and it has also been shown that APH-1a exists in two C-terminal splice forms, APH-1aS and APH-1aL (Francis et al. 2002; Goutte et al. 2002).

All four components are essential for complex stability and activity. Loss of any subunit abolishes proteolysis (Pardossi-Piquard et al. 2009). However, some experimental lines of evidence clearly suggest that in some cases not all subunits are required for proteolytic activity of the complex. Futai and colleagues (2009) demonstrated that nicastrin might be dispensable for the formation of the active complex providing that PS1 bears one out of 15 specific mutations. Most prominent results were obtained when the crucial Ser438, localized in the middle of TMD9, was replaced by a proline residue. It is worth remembering that TMD9 is proposed to be an NCT binding and substrate recognition site, and thus the introduction of Pro might lead to serious conformational changes (Futai et al. 2009). However, there are conflicting data with respect to the role of PEN-2 in the complex. In one experiment, $\gamma$-secretase activity has been reconstructed by an in vitro assay using proteoliposomes. The ability to process the APP substrate was accomplished by full-length wild-type PS1 alone, but only after adding purified PEN-2 protein. No other subunit was required. Thus, two notions have been thus suggested that the heterodimer of PS1 is sufficient for an in vitro APP processing, and that PEN-2 is necessary and sufficient for endoproteolytic activation of PS1 (Ahn et al. 2010). On the contrary, the data of Mao et al. (2012) indicate that PEN-2 is dispensable for endoproteolysis of PS1, but together with APH-1 and NCT it is required for the stabilization of PS's endoproteolytic products (Mao et al. 2012). This is at least partially confirmed by crystallographic data suggesting PEN-2 binds to the opposite side of CTF domain of PS1 than APH-1 and nicastrin ( $\mathrm{Li}$ et al. 2013). In general, it is also believed that the subunit stoichiometry within the $\gamma$ secretase complex is 1:1:1:1 for all four proteins: PS1 or PS2, APH-1, PEN-2, NCT (Osenkowski et al. 2009; Lichtenthaler et al. 2011).

\section{Building up the complex}

Gamma-secretase is a high-molecular-weight complex, but its exact size has not been satisfactorily determined due to significant differences in results depending on the method used. Reaching its final size and composition as well as subcellular localization has also not been fully elucidated. Many experimental lines of evidence show that $\gamma$-secretase subunits are localized in almost all compartments of the endomembrane system, including the endoplasmic reticulum (ER), various Golgi-related elements, plasma membrane and numerous types of endo-, lyso- and phagosomes (Annaert and De Strooper 1999; Pasternak et al. 2003; Rechards et al. 2003; Jutras et al. 2005; Fukumori et al. 2006; Fassler et al. 2011). Moreover, assembly of the $\gamma$-secretase complex is also closely related to the trafficking of the maturing subunits and subcomplexes through the endomembrane system (Fig. 2). It is now generally accepted that all $\gamma$-secretase subunits are synthesized in ER. During synthesis, nicastrin is $N$-glycosylated to form so-called immature nicastrin (imNCT). It binds to APH-1 to assemble the first stable subcomplex. Most probably this subcomplex is formed within ER. The newly formed heterodimer imNCT/APH-1 binds to PS. However, recent findings indicate that although NCT and APH-1 can form a subcomplex in the absence of PSs, PS1 can also be co-immunoprecipitated with APH-1 in the absence of NCT and vice versa (Mao et al. 2012). The final step in the formation of $\gamma$-secretase complex is the incorporation of PEN-2 via its interaction with PS. This event is immediately followed by PS autoproteolysis. If PEN-2 is not present, the defective subcomplex is degraded via proteasomes. In a next step, a small portion (up to $5 \%$ ) of assembled $\gamma$-secretase traffics to the Golgi, where nicastrin is further $\mathrm{N}$-glycosylated to form mature nicastrin (mNCT). Proteins that are not immediately incorporated to stable 
subcomplexes are rapidly degraded. This explains the relatively short lifetime of free components compared to the long lifetime of incorporated ones. Finally, the mature complex moves on towards the plasma membrane and endosomes (Fig. 2). A detailed, but still incomplete model of the complex assembly process has been presented Dries and $\mathrm{Yu}$ (2008).

The intriguing observation is that although subunits of the $\gamma$-secretase complex are found in large quantities in the ER and Golgi apparatus, $\gamma$-secretase proteolytic activity can only be found at and in the close vicinity to the cell surface (Kaether et al. 2006a, b; Rajendran et al. 2006). There are suggestions that two separable pools of $\gamma$-secretase, inactive and active, can be distinguished in the cell. The inactive $\gamma$-secretase complexes comprise a significant majority (up to $95 \%$ ) of the whole pool and shuttle between the ER and Golgi. Only a small subset of $\gamma$-secretase complexes (not bigger than $5 \%$ ) is active, and is localized at the plasma membrane and in endosomal compartments (Pasternak et al. 2003; Kaether et al. 2006b; Dries and $\mathrm{Yu}$ 2008). In accordance with this notion, APP and the Notch receptor, the two best-studied $\gamma$-secretase substrates, are processed proteolytically in this cortical part of the endomembrane system, somewhat earlier than at the plasma membrane and/or in early endosomes (Kaether et al. 2006b). These data are also consistent with the recent identification of Rer1 protein (Retrieval to ER 1; Kaether et al. 2007), which was shown to act as "a quality control point" enabling only mature and properly folded complexes to exit the ER. Each $\gamma$ secretase subunit is equipped with unique ER-retention sequence motifs localized probably either in cytosolic loops or within transmembrane domains. Up to date, several novel ERretention signals have been identified, including sequences localized at $\mathrm{C}$ terminus and TMD4 of presenilin 1 (Kaether et al. 2004; Fassler et al. 2010), at the TMD1 of PEN-2 protein (Kaether et al. 2007), and in the TMD of nicastrin (Spasic et al. 2007). Following successful complex assembly the retention signals are masked, and ER export is possible (Kaether et al. 2007). Another observation worth mentioning here is that both $\gamma$-secretase activity and PS distribution within subcellular compartments is enriched in mitochondria-associated ER membranes (MAMs; Area-Gomez et al. 2009). Earlier experiments indicated that APP processing depends on $\gamma$-secretase activity localized within lipid rafts. Recently, it has been demonstrated that MAMs display characteristics typical for lipid rafts. Therefore, it was suggested that the earlier identified $\gamma$-secretase-enriched lipid rafts were in fact MAMs (Urano et al. 2005; Kosicek et al. 2010; Area-Gomez et al. 2012). Moreover, key functions of MAMs, such as calcium homeostasis, cholesterol metabolism, synthesis and transfer of phospholipids, seem to be dependent on the presence of PSs. In accordance with this notion, an increased ER-mitochondria
Fig. 2 The four $\gamma$-secretase components are synthesized in the endoplasmic reticulum $(E R)$, where the complex is gradually assembled. Firstly, imNCT (violet)/APH-1 (red) subcomplex is formed. PS holoprotein (yellow) binds to imNCT/APH-1 subcomplex. Heterotrimeric $\mathrm{PS} / \mathrm{NCT} / \mathrm{APH}-1$ subcomplex is further stabilized by incorporation of PEN-2 (green). In the stabilized complex, PS catalyses autoendoproteolysis within the loop between TMD 6 and TMD7. In the heterotetrameric complex retention signals within TMDs are masked and as an ER export is possible. Upon reaching transGolgi imNCT is fully maturated to $\mathrm{mNCT}$ and mature, active $\gamma$-secretase is assembled. Unincorporated subunits can be retrieved to the ER, possibly via the action of Rerlp. The mature $\gamma$-secretase can localize in many subcellular compartments, e.g., GA, TGN, plasma membrane, endosomes, lysosomes as well as MAMs

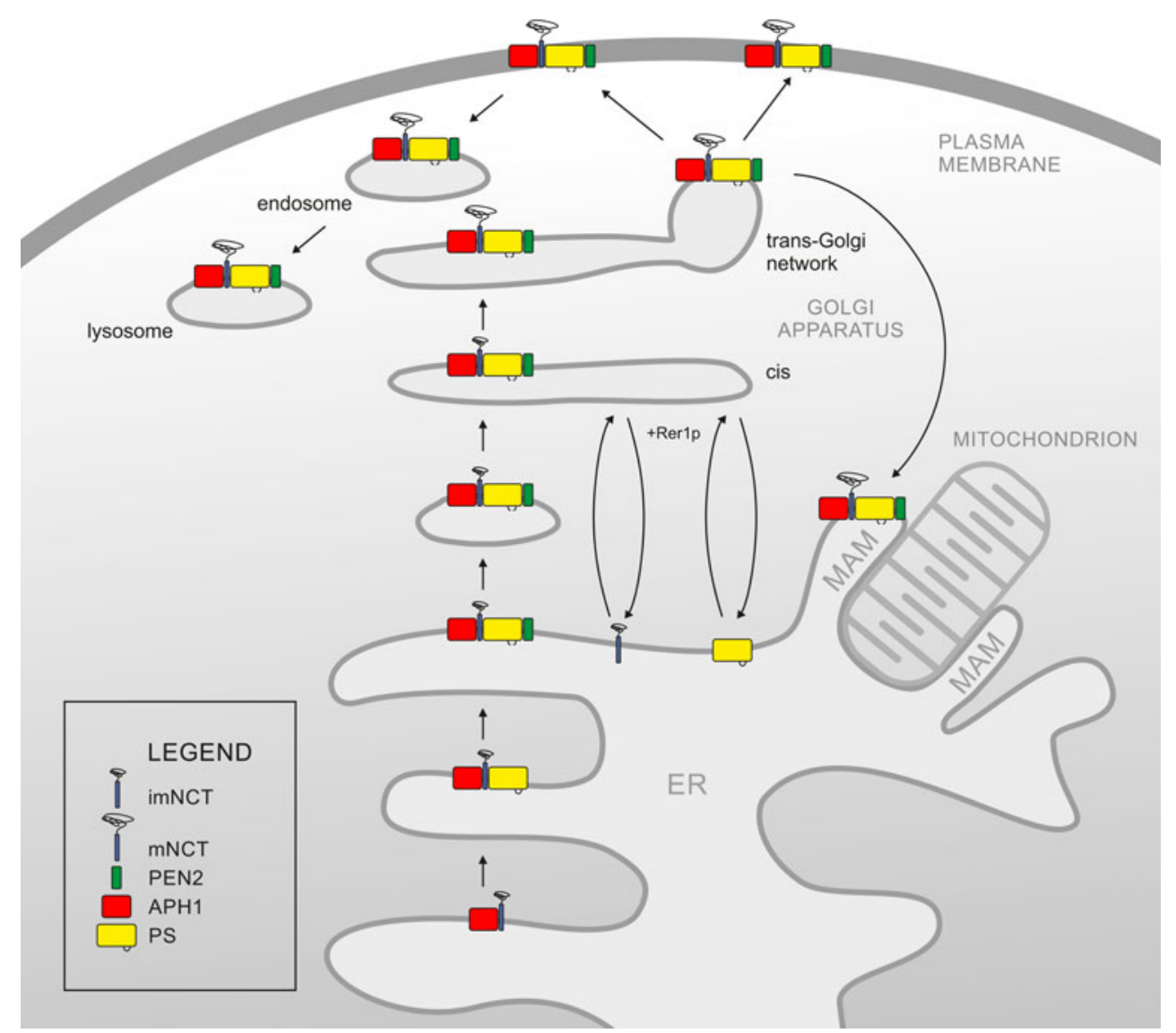


apposition in cells lacking both PS1 and PS2, and in cells expressing FAD-linked PS has been observed (Area-Gomez et al. 2012).

\section{To cleave or not to cleave? Substrate specificity of the $\gamma$-secretase}

As mentioned above, the two $\gamma$-secretase substrates, APP and the Notch receptor, have been characterized in detail. However, at present there are more than sixty different substrates known, and most of them are type I transmembrane proteins (McCarthy et al. 2009). These include ApoER2 (May et al. 2003; Hoe and Rebeck 2005), the ligand of Notch receptor Delta (Six et al. 2003; LeVoie and Selkoe 2003; Ikeuchi and Sisodia 2003; Bland et al. 2003), E-cadherin (Marambaud et al. 2002), Erb4 (Ni et al. 2001; Lee et al. 2002), insulin receptor (Kasuga et al. 2007), and Nectin- $1 \alpha$ (Kim et al. 2002; McCarthy et al. 2009). Many other $\gamma$ secretase substrates also play significant roles in various crucial biological processes, like development, cell-cell adhesion, intracellular signaling. For example, neurexin, the recently discovered substrate of $\gamma$-secretase, takes part in synapse formation and functioning (Restituito et al. 2011; Saura et al. 2011). It is worth to mention here that synaptic dysfunction is also another major feature in early development of Alzheimer disease (Knobloch and Mansuy 2008). On the other hand, the distribution of known $\gamma$-secretase substrates across species is very intriguing. Basically all of them are proteins occurring exclusively in Metazoa, even though $\gamma$ secretase activity has been reported in the slime mold, $D$. discoideum. Similarly, genes coding for $\gamma$-secretase subunit homologs have been recognized in plant genomes (McMains et al. 2010; Smolarkiewicz 2012), but no substrate of non-metazoan origin has yet been identified.

Proteolytic activity of the $\gamma$-secretase complex has been intensively studied due to the importance of $\gamma$-secretasedependent APP proteolysis in pathogenesis of Alzheimer disease. Some mutations in PSs predispose for development of FAD and these FAD-linked PS mutants are responsible for the elevation in ratio of pathogenic $A \beta 42$ to $A \beta 40$. Gammasecretase-dependent proteolysis requires earlier ectodomain shedding by different proteases. In the case of APP, the ectodomain can be cleaved by a metalloprotease from the ADAM (a disintegrin and metalloproteinase) family or by $\beta$-secretase (BACE; $\beta$-site APP cleaving enzyme). ADAM and BACE are also transmembrane proteins, but their substrates are cleaved within the juxtamembrane domain. For $\gamma$ secretase cleavage there is no requirement for a specific sequence within the substrate, but the conformation of the substrate's juxtamembrane domain, TMD or ICD itself have a substantial influence on recognition and cleavage (Ren et al. 2007; Hemming et al. 2008). Details of $\gamma$-secretase action come from the studies on APP processing which can be cleaved along two distinct proteolytic pathways. Within the amyloidogenic pathway, the ectodomain located in N-terminal portion of AP protein is shed by BACE. The membrane bound APP-CTF is then cleaved by $\gamma$-secretase at several $\gamma$ sites and this results in the generation of $A \beta$ peptides with different $C$ termini. In the non-amyloidogenic pathway, which is also common for other $\gamma$-secretase substrates, the ectodomain is shed by the ADAM enzyme, and this is followed by cleavage of the $\mathrm{C}$-terminal domain at $\varepsilon$ site, which is located near the cytoplasmic border of the membrane. The resulting AICD is then released (Yu et al. 2001; Weidemann et al. 2002; Zhao et al. 2005). Differential regulation of $\gamma$-cleavage and $\varepsilon$-cleavage has been reported (Kume and Kametani 2006). It has also been shown that different factors, like $\mathrm{pH}$, salt concentration, FAD-linked mutations in PS, affect differentially the overall proteolytic activity ( $\varepsilon$-cutting) and processivity (trimming) of $\gamma$-secretase (Quintero-Monzon et al. 2011). A detailed overview of proteolytic processing by $\gamma$-secretase has recently been published by Barthet et al. (2012).

It is not completely clear how the different subunits of $\gamma$ secretase contribute to substrate docking and cleaving. It seems that the major obstacle here lies in the lack of structural information related to the whole complex composed of four subunits. Cross-linking studies showed that PS CTF lies closely to PS NTF, PS CTF to APH-1, APH-1 to NCT, and PS NTF to PEN-2 (Steiner et al. 2008). These results give the basic view on interactions within the complex, and were confirmed by other approaches (Fraering et al. 2004; Kim and Sisodia 2005; Watanabe et al. 2005). More details can be found with respect to PS structure. In 2006 the hydrophilic cavity, formed by TMD6 and TMD7, and containing YD and GXGD motifs, was discovered. This cavity or pore was suggested as a catalytic site (Sato el al. 2006; Tolia et al. 2006). Two important points have been recently added to this observation through crystallographic analysis of the archeal protein MCMJR1, a PS homolog. First, it seems that the cavity is formed in such a way that water molecules have unrestricted access to the catalytic active. Second, the space surrounded by TMD6 and TMD9 is most probably the entry point for substrates ( $\mathrm{Li}$ et al. 2013). Other TMDs and amino acid residues, such as the PAL motif, TMD1, and TMD9 were also reported to be involved in formation of hydrophilic cavity (Sato et al. 2008; Tolia et al. 2008; Takagi et al. 2010). Recent observations of $\gamma$-secretase and its trimeric pre-activation complex composed of the PS holoprotein, APH-1 and NCT, confirmed that the PS active site faces the hydrophilic chamber. There was also an indication that incorporation of PEN-2 may contribute to the maturation of active site architecture (Renzi et al. 2011).

For the $\gamma$-secretase complex, the substrate binding site is considered to be distinct from the active site (Esler et al. 2002). Nevertheless, results on the contribution of individual subunits 
to substrate binding seem not to be fully conclusive. For example, although NCT was reported to function as a substrate recognition site (Shah et al. 2005; Dries et al. 2009), it was also demonstrated that $\gamma$-secretase composed of PS1/PEN-2/APH1a can cleave Notch and APP in the absence of nicastrin (Zhao et al. 2010). One should also bear in mind that in the activity test performed in liposomes PS1 was able to cleave substrates in the absence of NCT, APH1, PEN-2 (Ahn et al. 2010). In all cases, however, autocatalytic endoproteolysis is an absolute prerequisite for the activation of PS1. There are also some indications that APH-1 might be involved in substrate recognition (Chen et al. 2010). Some support for this comes from a series of elegant co-immunoprecipitation experiments showing that NCT/APH-1 subcomplex is sufficient for interactions with CTF $\beta$ of APP, the initial substrate of $\gamma$-secretase. However, as higher amounts of CTF $\beta$ were coimmunoprecipitated with NCT than with other $\gamma$-secretase components, the major role of nicastrin in substrate binding was again supported (Mao et al. 2012).

With respect to substrate docking, the respective site within PS is localized very close to the active site and both possibly even overlap (Kornilova et al. 2005). The substrate's juxtamembrane or transmembrane domains also influence cleavage, and ectodomain shedding is not the only prerequisite for the formation of an appropriate substrate structure (Ren et al. 2007; Hemming et al. 2008). There are some indications that extracellular and intracellular domains of the substrates may alsoinfluence proper positioning on the PS docking site (Lichtenthaler et al. 2011).

Strong differences in the phenotypes of PS1 and PS2 mutants (Herreman et al. 1999) suggest that there will also be variances in the activities of PS1- or PS2-containing $\gamma$ secretase complexes. Experiments conducted by Frånberg et al. (2011) showed that PS2 has a minor contribution to $\gamma$ secretase activity, especially for cleavage of the most important substrates: APP and Notch. Comparative analyses of PS1- and PS2-containing $\gamma$-secretase complexes were done with the use of the yeast recombinant system. Complexes with PS2 were similarly efficient in $\beta$-amyloid production as complexes having PS1. However, PS2 was reported less likely to form $\gamma$ secretase complexes (Yonemura et al. 2011). It is worth mentioning that in these experiments an APH-1a-L splicing variant was used, and this might suggest the promotion of alternative complex binding patterns by APH-1a-S, e.g., with immature nicastrin (Yonemura et al. 2011). Differences between the functioning of PS1 and PS2 were also observed with respect to calcium homeostasis (Zampese et al. 2011). Activity of the whole complex could be regulated by various interacting proteins, such as the transmembrane trafficking protein $21 \mathrm{kDa}$ (TMP21) or $\gamma$-secretase-activating protein (gSAP), which modulates $\gamma$-site cleavage of APP (Chen et al. 2006; He et al. 2010; St George-Hyslop and Fraser 2012). This implies that there might be a wealth of differently composed $\gamma$-secretase complexes, and variable substrate specificity, activities, and developmental distribution of different complexes might contribute to the development of neurodegenerative disorders. On the other hand, it also shows a potential for the determination of new targets for the treatment of those diseases (Ma et al. 2005; Chen et al. 2006; Zhou et al. 2005; He et al. 2010; Placanica et al. 2010; St. George-Hyslop and Fraser 2011).

\section{The role of the gamma-secretase complex: beyond the beaten track}

Gamma-secretase complex is one of the major players in Regulated Intramembrane Proteolysis (RIP), thus contributing greatly to the control of communication between cells and extracellular environment (Brown et al. 2000; Urban et al. 2001; Lichtenthaler et al. 2011). Occurrence of ICDs acting as signaling molecules, affecting gene expression was firstly proved for Notch intracellular domain (NICD), and afterward proposed also for others, such as the APP intracellular domain (AICD) and ICD of CD46 (Beckett et al. 2012; Nakayama et al. 2011; Weyand et al. 2010). Below, however, we will concentrate on other aspects of $\gamma$-secretase action.

\section{Lessons from ancient relatives}

As mentioned earlier, homologs of PS, APH-1, PEN-2, NCT were identified also in nonmetazoan genomes. As there are still numerous question marks concerning the structure and functions of $\gamma$-secretase in Metazoa, a closer look at the evolutionary distant organisms harboring $\gamma$ secretase components might be a starting point for a broader, comprehensive analysis.

A moss, Physcomitrella patens which quickly became one of the model organisms in plant sciences, was the first nonanimal organism in which the role of PS and the other $\gamma$ secretase subunit, nicastrin, has been shown. Physcomitrella turned out to be a convenient model for research on $\gamma$-secretase homologues. It harbors all four components of the complex, but the genome contains only one copy of presenilin gene (PpPS). Moreover, no major known substrate, including Notch and APP, has been yet identified in plants. Physcomitrella is thus a suitable model for searching the biological functions of $\gamma$ secretase subunits (Khandelwal et al. 2007). A null mutant of presenilin $(\mathrm{Pp} \Delta \mathrm{ps})$ displayed pleiotropic phenotypic changes with visible morphological and physiological abnormalities. Mutant plants showed an uncommon growth pattern and impaired chloroplast movement (Khandelwal et al. 2007). Importantly, plastid movement in plants is well-known to be driven by the actin cytoskeleton (Anielska-Mazur et al. 2009), and PS in animals has also been shown to interact with some cytoskeleton-associated proteins, e.g., filamin (Zhang et al. 1998; Guo et al. 2000). The uptake of FM4-64 dye, a common 
endocytosis marker, was visibly impaired in $\mathrm{Pp} \Delta \mathrm{ps}$ indicating that PS might be necessary for proper membrane internalization and trafficking. The observed phenotype could be rescued by both native PS and a mutant form lacking the aspartyl residues crucial for PS activity. Interestingly, the phenotype could also be rescued by two identical forms of human PS. Looking in another direction, PpPS was unable to recognize common Notch1-based substrates in PS-deficient mouse fibroblasts. On the other hand, it could rescue accelerated proliferation in PS-deficient mouse embryonic fibroblasts, a function which is usually thought to be independent of $\gamma$-secretase proteolysis. All this data suggests that the role of PS in P. patens is not related to $\gamma$-secretase activity. However, this does not necessarily mean that other subunits are dispensable. It was shown that a null mutation in the P. patens homologue of nicastrin exhibits a similar phenotype as the PS mutant, suggesting strict interdependence between these two $\gamma$-secretase subunits (Khandelwal et al. 2007). Although detailed function of $\gamma$ secretase subunits in Physcomitrella still remains unclear, these data suggest that there might be a broader, evolutionary conserved function of the complex, or its individual subunits.

PS and other $\gamma$-secretase subunit orthologues have also been identified in $D$. discoideum. Similar to the situation in plants, this ancient eukaryote lacks any obvious equivalents of APP, Notch or any other characterized $\gamma$-secretase substrate. Most importantly, wild type Dictyostelium is capable of processing ectopically expressed human APP, and APP processing in null mutant strains of $\gamma$-secretase subunits is impaired (McMains et al. 2010). PSs were also shown to be crucial for Dictyostelium cell fate determination and regulation of phagocytosis. This suggests that the ancient biological role of $\gamma$ secretase exceeds beyond frames known from animal studies. One of the possible suggestions would be that PS $/ \gamma$-secretase activity could arise before metazoan expansion and independently of Notch signaling. This again leads to a debate on the original, ancient biological function of the complex.

\section{Eat me}

One of the concepts assumes that $\gamma$-secretase or PS itself might originally be involved in the degradation and recycling of membrane proteins (Lichtenthaler et al. 2011). In this view, it would have to act as a "membrane proteasome" (Kopan and Ilagan 2004), acquiring signaling functions related to $\gamma$ secretase cleavage later in evolution (McMains et al. 2010). This would be consistent with the observation that PSs may regulate cell signaling by targeting membrane proteins for degradation or endosomal recycling. Evidence has accumulated indicating the possible role of $\gamma$-secretase in phagocytic or autophagy-mediated lysosomal protein degradation in Metazoa (Neely et al. 2011) as well as in D. discoideum (McMains et al. 2010). Autophagy involves the degradation of cellular components (organelles) or long-lived proteins and aggregates in order to restore nutrition and to balance protein synthesis and degradation during normal development, programmed cell death or in response to starvation. It is evolutionary conserved in all eukaryotes (Rabinowitz and White 2010; Neely et al. 2011). Phagocytosis, on the other hand, encompasses the internalization and degradation of large particles, organelles or cells up taken from exterior. In single-cell hetetrotrophic Protista it is utilized for nutrient uptake while in multicellular Metazoa it is involved in immunological homeostasis (Underhill and Ozinsky 2002). Both pathways, phagocytosis and autophagy, meet in lysosomes where degradation of the cargo is completed.

PS1 and nicastrin were shown to co-localize in murine lysosomes and $\gamma$-secretase activity against APP could also be detected in lysosomal membranes (Pasternak et al. 2003). Moreover, lysosomal proteolysis and autophagy require PS1 (Lee et al. 2010). In PS null mutants both lysosomal proteolysis and autophagosome clearance were affected. Cathepsin activation caused by the failure of PS1-dependent targeting of the V-ATPase V0a1 subunit to lysosomes was identified as a molecular mechanism leading to the impairment in autolysosome acidification (Lee et al. 2010). On the other hand, in basal autophagy-defective mutants of HEK293 cells (Human Embryonic Kidney 293), the expression of PS1 was stimulated while the production of $A \beta$ and cleavage of Notch1 were significantly increased (Ohta et al. 2010). Thereafter, Neely and colleagues (2011) have demonstrated that PS is necessary for autophagy-mediated proteolysis in a $\gamma$-secretase independent manner. Although loss of PSs increased the number of lysosomes and autophagosomes in cells, the overall efficiency of protein degradation by autophagy was significantly reduced. On the contrary, no differences in autophagic efficiency could be seen in cells treated with $\gamma$-secretase inhibitors, and this suggested that PS could have functions different than proteolytic ones (Neely et al. 2011). Other explanations are still possible. Impaired lysosomal fusion capacity and accumulation of endomembranes in PS-deficient cells were recently shown to result from alterations in lysosomal calcium storage/release rather than changes in lysosomal acidification (Coen et al. 2012). Similarly, PS loss in PS knockout fibroblasts leads to altered lysosomal calcium levels and changes in two-pore channel expression and dimerization (TPC1-TPC2; Neely Kayala et al. 2012). Other results point to the importance of TFEB, a master transcriptional regulator of lysosomal biogenesis and autophagy. According to these observations PSs regulate pathways critical for lysosomal biogenesis, but in a TFEB mRNA independent manner (Zhang et al. 2012). Finally, defective autophagy was shown to be involved in the pathogenesis of Alzheimer's disease, also at the very early stages of disease (Nixon and Yang 2011).

Gamma-secretase subunits are also indispensable for efficient phagocytosis. The activity of the complex was found 
in phagosome membranes from immune response-related cells of two evolutionary distant organisms: murine macrophages and Drosophila S2 phagocytes (Jutras et al. 2005). They were also shown to be crucial for phagocytosis of $A \beta$ conducted by microglia (Farfara et al. 2011), and endocytotic nutrient uptake by Dictyostelium (McMains et al. 2010). All these data suggest that PSs alone or in the $\gamma$ secretase complex might play a crucial role in membrane and protein trafficking events. Vesicle formation occurs not only during autophagy, but also during other processes (e.g., endocytosis).

Endocytosis: passive cargo or active player?

It seems that $\gamma$-secretase subunits specifically interact with proteins known for their direct involvement in trafficking. A protein-protein interaction study (Dumanchin et al. 1999) showed that human PS1 and PS2 interact with Rab11 - a small GTPase known to be a master regulator of protein transport via recycling endosomes (Jing and Prekeris 2009). Similarly, syntaxin 5 and syntaxin 1A, two SNAREs involved in Golgi trafficking and synaptic vesicle fusion, respectively, also bind to PS (Smith et al. 2000; Suga et al. 2005). In addition, localization of active $\gamma$-secretase complexes in synaptic vesicles has been demonstrated (Frykman et al. 2010). PS was shown to be involved in $\gamma$-secretase-dependent processing of nectin 1 and 3, adhesion molecules involved in establishing cell-cell adherent junctions at synapses (Kim et al. 2011). Moreover, there are some indications that $\gamma$ secretase might be essential for the regulation of neurotransmitter release (Pratt et al. 2011), although the underlying mechanism - direct involvement or regulation of calcium homeostasis — is still not fully defined (Zhang et al. 2009; Pratt et al. 2011).

Although $\gamma$-secretase complexes could be found in many compartments of the endomembrane system, activity of the complex is practically restricted to the cell surface and vesicles located at the cell cortex. However, the question on the biological function of $\gamma$-secretase in membrane trafficking still remains open. Much effort has been made to determine whether $\gamma$-secretase itself is involved in regulation of vesicle trafficking or whether is it just internalized from the plasma membrane to endosomes as a "cargo" destined for degradation. The prevailing view now is that $\gamma$-secretase participates in the orchestration of various protein trafficking events (Esselens et al. 2004; Wilson et al. 2004; Repetto et al. 2007; Zou et al. 2008; Nahalkova et al. 2010). Apart from the already discussed role in autophagy and phagocytosis, new lines of evidence have come from studies on receptor-mediated endocytosis (RME, also known as ligand-induced endocytosis). RME is an evolutionary conserved mechanism, present in all eukaryotes, in which ligand-bound receptors become internalized and are trafficked along various compartments of endocytotic pathway.
In animals, receptors for Notch, epidermal growth factor (EGF), transferrin or low-density lipoprotein (LDL), for example, are all internalized in this way (Ceresa 2006; Fürthauer and González-Gaitán 2009; Grant and Donaldson 2009). Some of these receptors play a role as carrier proteins, e.g., the LDL receptor, and some act as a trigger for signaling cascades, e.g., EGFR. RME has also been extensively investigated in plants, and examples include receptors for flagellin (FLS2; FLAGELLIN-SENSING 2) and brassinosteroids (BRI1; BRASSINOSTEROID-INSENSITIVE 1) (Geldner and Robatzek 2008; Irani and Russinova 2009).

In early studies, ligand-induced endocytosis of signaling receptors was considered as a negative regulator of signal transduction. It was usually thought that receptor internalization would act as the limiting factor simply by reducing the number of receptors available at the cell surface. However, more and more data indicate that there is a strong functional link between endocytosis and signaling, restricted not only to signal attenuation (Sorkin and Zastrow 2009). Some receptors continue signaling until late stages in the endocytic pathway, and some become activated only after internalization. Therefore, recent views present endosomes as "motile signaling platforms" (Šamaj et al. 2005) and intracellular trafficking of surface receptors as an integral part of signal transduction (Sadowski et al. 2009; Shilo and Schejter 2011). As some of the $\gamma$-secretase interacting partners have been shown to act as plasma membrane receptors, and all of them were shown to be internalized by RME, an interesting question on the involvement of $\gamma$-secretase in receptor trafficking has been posed. Indeed, partial loss of $\gamma$-secretase function led to the decreased capacity of cells to internalize the LDL receptor via endocytosis, and resulted in elevated levels of LDLR in the plasma membrane (Tamboli et al. 2008). Similarly, endocytosis of the transferrin receptor seems to be impaired in the absence of active $\gamma$-secretase. Data from Zhang and colleagues (2006) clearly demonstrated that $\gamma$-secretase activity is required for normal endosomal recycling. By means of pharmacological compounds and knock-out lines a significant delay in the trafficking of transferrin through the recycling compartment was detected.

The Notch receptor is one of best studied substrates for $\gamma$ secretase. In animals, Notch signaling pathway is a highly conserved system involved mainly in the control of multiple cell differentiation processes during embryonic and adult life (Nichols et al. 2007). In the absence of its ligand, the Notch receptor is continuously internalized and degraded in lysosomes. However, following ligand binding, two consecutive proteolytic events occur. First, most of the extracellular domain of the Notch receptor is shed by ADAM protease. Then it becomes accessible for $\gamma$-secretase, which releases its intracellular part to act as a transcription factor. Many experimental clues indicate that $\gamma$-secretase-regulated intramembrane proteolysis of the Notch receptor is conducted in endosomes 
rather than at the plasma membrane as was previously thought (Nichols et al. 2007; Brou 2009; Sorkin and von Zastrow 2009; Le Bras et al. 2011). One can speculate that not only Notch cleavage but also endocytosis are somehow dependent on $\gamma$-secretase activity, but this still requires further research (Andersson et al. 2011; Le Bras et al. 2011). One should also bear in mind, that contradictory evidence is also available (Sorensen and Conner 2010).

Another example of interplay between protein trafficking and signaling is EGFR endocytosis (Sorkin and von Zastrow 2009), and the role for $\gamma$-secretase has been already indicated. In PS mutants, elevated levels of EGFR were detected due to its delayed turnover. Moreover, ligand-induced signaling was noticeably prolonged in PS mutants and EGFR trafficking from early endosomes to lysosomes was critically impaired (Repetto et al. 2007). Endocytic trafficking was shown to be required for receptor phosphorylation and activated EGFR was localized even to late compartments of endocytic pathway (Sadowski et al. 2009; Zwang and Yarden 2009). To perform their functions endosomes undergo dynamic movements along microtubules and actin filaments. Interestingly, the signaling output of the EGF receptor was shown to be dependent on the endosome localization within the cell. For example, mistargeting of late endosomes with EGFR cargo to the cell periphery resulted in prolonged signaling (Taub et al. 2007). It is tempting to speculate that $\gamma$-secretase could play a dual role, both in receptor internalization and recycling, and in the reorganization of the cytoskeleton.

An elegant example linking: $\gamma$-secretase cleavage, signaling and endocytosis, is the proteolytic processing of protocadherin proteins (Pcdh; Buchanan et al. 2010). Protocadhedrins are single-pass transmembrane proteins predominantly expressed in the nervous system. They constitute the largest subgroup within the cadherin superfamily and play critical roles in intercellular adhesion and cell-to-cell communication (Morishita and Yagi 2007). Processing of Pcdh involves the $\gamma$-secretase-dependent release of ICD which is active both in the cytoplasm and in the nucleus (Parks and Curtis 2007). It has been demonstrated that the $\gamma$-secretase-dependent cleavage of $\operatorname{Pcdh} \alpha$ requires endocytosis. There were also suggestions that in this case, endocytosis of Pcdh $\alpha$, extracellular domain cleavage, $\gamma$-secretase cleavage, and ESCRT-dependent trafficking maybe co-regulated during differentiation (Buchanan et al. 2010). Interestingly, the endosomal sorting complex (ESCRT) also directs Notch-positive endosomes to the multivesicular body pathway and the lysosome (Vaccari et al. 2008).

On guard of the calcium flux

One of the concepts on the ancient function of PSs is related to the hypothetical formation of a calcium leak channel (Selkoe and Wolfe 2007). Although there are many hints pointing to the involvement of PS in calcium homeostasis, conclusive evidence is still to be gathered. Mammalian PSs have been reported to regulate the calcium homeostasis of intracellular stores and to control neurotransmitter release and long-term potentiation, which are regulated by intracellular $\mathrm{Ca}^{2+}$ release. Interestingly, the influence of PSs on $\mathrm{Ca}^{2+}$ signaling and intracellular $\mathrm{Ca}^{2+}$ flux seems to be independent from $\gamma$-secretase activity (Zhang et al. 2010; Ho and Shen 2011). On the contrary, control of spontaneous neurotransmission through modulation of low-level tonic $\mathrm{Ca}^{2+}$ influx into presynaptic axon terminals in hippocampal neurons was reported as being $\gamma$-secretase-dependent (Ho and Shen 2011; Pratt et al. 2011). However, if $\mathrm{Ca}^{2+}$ is released from intracellular stores the neurotransmitter release is becoming $\gamma$-secretase-dependent (Pratt et al. 2011). Apart from $\gamma$-secretase activity, several other mechanisms by which PSs affect $\mathrm{Ca}^{2+}$ homeostasis have been proposed: (1) formation of an $\mathrm{ER} \mathrm{Ca}^{2+}$ leak channel by PS holoprotein (Tu et al. 2006); (2) activation of the sarco/ER $\mathrm{Ca}^{2+}$-ATPase (SERCA) pump (Green et al. 2008); (3) increasing the activity of the inositol triphosphate receptor $\left(\operatorname{InsP}_{3} \mathrm{R}\right)$ $\mathrm{Ca}^{2+}$ release channel in response to low [ $\left.\mathrm{InsP}_{3}\right]$ (Müller et al. 2011a); (4) increasing the number of contact sites between ER and mitochondria, and thus favoring $\mathrm{Ca}^{2+}$ transfer between ER and mitochondria (Zampese et al. 2011); (5) potentiation of Ryanodine Receptor (RyR) activity by N-terminal fragment regulation (Rybalchenko et al. 2008); and (6) $\mathrm{PIP}_{2}$-mediated regulation of Transient Receptor Potential Melastatin Related 7 (TRPM7) channel (Oh et al. 2012).

Many of the known FAD-linked PSs turned out to enhance $\mathrm{Ca}^{2+}$ release in response to $\mathrm{InsP}_{3}$-generating agonists (Ito et al. 1994; Hirashima et al. 1996; Etcheberrigaray et al. 1998). PSs were suggested to play a major role in ER $\mathrm{Ca}^{2+}$ leak and the disruption of $\mathrm{ER} \mathrm{Ca}^{2+}$ leak function of PSs results in increased $\mathrm{Ca}^{2+}$ levels in ER in, e.g., PS knock-out fibroblasts and double PS knock-out murine hippocampal neurons (Tu et al. 2006; Zhang et al. 2010). Contradictory results concerning some FAD-linked PS-derived $\left[\mathrm{Ca}^{2+}\right]_{\mathrm{ER}}$ shifted attention to the hyperactivity of $\mathrm{ER} \mathrm{Ca}^{2+}$ release channels (Cheung et al. 2008, 2010). In addition, expression of FAD-linked PS results in constitutive InsP $_{3}$ R-CaMKIV-CREB signaling due to ER $\mathrm{Ca}^{2+}$ release through $\operatorname{InsP}_{3} \mathrm{R}$ channel (Müller et al. 2011a). This pathway alters gene expression in the brain and enhances ROS generation and cell death as well as the cytotoxic effects of $A \beta$ oligomers (Müller et al. 2011a, b).

Another possible explanation as to how PSs could influence $\mathrm{Ca}^{2+}$ homeostasis centers on the regulation of TRPM7 channel by PSs. Oh et al. (2012)) found that this control was independent from $\gamma$-secretase activity, was not dependent on a TRPM7 protein level, and was mediated by $\mathrm{PIP}_{2}$ levels. Earlier observations of FAD-linked PS mutations showed the elevated activity of phospholipase $\mathrm{C}$ (Cowburn et al. 2007), providing a link via modulation of the $\mathrm{PIP}_{2}$ level. It has also been suggested that this regulation of $\mathrm{Ca}^{2+}$ influx 
operates following the depletion of extracellular $\mathrm{Ca}^{2+}$ stores (Oh et al. 2011).

Forming a leak channel by PSs and the influence of FADlinked PS mutations on channel conductance were first described by Tu et al. (2006). It was hypothesized that the PS holoprotein is responsible for the formation of ${\mathrm{ER} \mathrm{Ca}^{2+}}^{2+e a k}$, contrary to the PS contribution to $\gamma$-secretase-dependent proteolysis, which requires activating endoproteolysis of PS (De Strooper and Annaert 2010). Indeed, recent data indicate that PS's catalytic hydrophilic cavity may constitute a $\mathrm{Ca}^{2+}$-conductance pore (Nelson et al. 2011). The existence of distinct forms of $\gamma$-secretase in different types of cells, with various forms of PS1, could open the possibility for both structural and functional diversity of the $\gamma$-secretase complex (Supnet and Bezprozvanny 2011). In fact, an atypical $\gamma$-secretase complex with significantly altered subunit stoichiometry was already detected in hematopoietic cell line (Placanica et al. 2010). Some controversies have been raised, however, with recently published data from Shilling et al. (2012). They have found that PS did not form a calcium leak channel, and that $\mathrm{ER} \mathrm{Ca}^{2+}$ dynamics was not altered in double knock-out MEF cells. PS holoprotein and FAD-link PS also did not affect ER $\mathrm{Ca}^{2+}$ dynamics. Nevertheless, PS's influence on total cellular, but not ER, ionomycin-induced $\mathrm{Ca}^{2+}$ release in fibroblasts has been confirmed. Moreover, the origin of this controversy has been identified too, and the specific localization of $\mathrm{Ca}^{2+}$ indicators to the ER was shown to be required (Shilling et al. 2012).

Interesting results were obtained on the specific role played by PS2 in the modulation of ER-mitochondria interactions and $\mathrm{Ca}^{2+}$ cross-talk (Zampese et al. 2011). FAD-linked PS2 mutants increased physical interactions between ER and mitochondria and strengthened $\mathrm{Ca}^{2+}$ transfer between both organelles. Reinforcement of ER-mitochondrial interactions was independent from both $\gamma$-secretase activity and PS2 autoproteolysis. However, the full-length form of PS2 was anyway necessary. It was also suggested that $\mathrm{Mfn}-2$, a protein directly bridging ER-mitochondria by homotypic interactions was important in this process (Zampese et al. 2011; AreaGomez et al. 2012). Similarly, suggestions were presented that this is the role of PS in MAMs formation, therefore providing a link between increased ER-mitochondrial interactions, alterations in calcium homeostasis, and PSs, as enrichment of MAMs could involve proteins important for $\mathrm{Ca}^{2+}$ homeostasis and functionally related to PS, like the ryanodine receptor (Garcia-Perez et al. 2008), and the inositol-1,4,5-triphosphate receptor $\left(\mathrm{IP}_{3} \mathrm{R}\right)$ (Hayashi et al. 2009).

It should also be remembered that PSs interact with many other proteins related to $\mathrm{Ca}^{2+}$ signaling, like sorcin, calmodulin, calsenilin, calmyrin, calpain (Buxbaum et al. 1998; Shinozaki et al. 1998; Stabler et al. 1999; Pack-Chung et al. 2000). These results add to the observed close functional relationship between PSs and calcium signaling and make the involvement of PS in intramembrane proteolysis more understandable. Moreover, altered $\mathrm{Ca}^{2+}$ signaling precedes the appearance of plaques and tangles and could contribute to neuronal cell death during AD (Bezprozvanny and Mattson 2008). This makes the issue of PSs and calcium regulation even more interesting and important.

\section{Conclusions}

In this review, the very many faces of PSs and $\gamma$-secretase complex have been discussed. In the last few years, many important data have been collected and our knowledge about PSs' and $\gamma$-secretase's versatile functions has greatly expanded. Many issues related to the mechanisms of PSs and $\gamma$ secretase influence on, e.g., calcium homeostasis and autophagy, are still unclear with many contradictory results have been published. On the contrary, the way of the complex assembly is now rather well characterized, although some important details on the role of individual subunits within the complex and on the mechanism of PS endoproteolysis are still missing. New substrates of $\gamma$-secretase are still being discovered and details of the molecular mechanism of proteolysis and regulation are being progressively elucidated. This issue in particular gives hope for the discovery of an efficient drug for Alzheimer's disease. At that moment, a picture is emerging showing much more versatile roles for both PS and $\gamma$-secretase than anybody had expected previously. From the discoveries made in distant groups of organisms, e.g., plants and slime molds, new details and new functions of those proteins are being deduced, providing also new hints of biomedical importance.

Acknowledgements Support for the projects NN303 360735 and N N303 813540 funded by the Polish Ministry of Science and Higher Education grants to P.W. is gratefully acknowledged.

Open Access This article is distributed under the terms of the Creative Commons Attribution License which permits any use, distribution, and reproduction in any medium, provided the original author(s) and the source are credited.

\section{References}

Ahn K, Shelton CC, Tian Y, Zhang X, Gilchrist ML, Sisodia SS, Li YM (2010) Activation and intrinsic $\gamma$-secretase activity of presenilin 1. Proc Natl Acad Sci USA 50:21435-21440

Andersson ER, Sandberg R, Lendahl U (2011) Notch signaling: simplicity in design, versatility in function. Development 138:3593-3612

Anielska-Mazur A, Bernaś T, Gabryś H (2009) In vivo reorganization of the actin cytoskeleton in leaves of Nicotiana tabacum L. transformed with plastin-GFP. Correlation with light-activated chloroplast responses. BMC Plant Biol 9:64

Annaert W, De Strooper B (1999) Presenilins: molecular switches between proteolysis and signal transduction. Trends Neurosci 22:439-443 
Area-Gomez E, de Groof AJ, Boldogh I, Bird TD, Gibson GE, Koehler CM, Yu WH, Duff KE, Yaffe MP, Pon LA, Schon EA (2009) Presenilins are enriched in endoplasmic reticulum membranes associated with mitochondria. Am J Pathol 175:1810-1816

Area-Gomez E, Del Carmen Lara Castillo M, Tambini MD, GuardiaLaguarta C, de Groof AJ, Madra M, Ikenouchi J, Umeda M, Bird TD, Sturley SL, Schon EA (2012) Upregulated function of mitochondria-associated ER membranes in Alzheimer disease. EMBO J 31:4106-4123

Bammens L, Chávez-Gutiérrez L, Tolia A, Zwijsen A, De Strooper B (2011) Functional and topological analysis of Pen-2, the fourth subunit of the gamma-secretase complex. J Biol Chem 286: 12271-12282

Barthet G, Georgakopoulos A, Robakis NK (2012) Cellular mechanisms of $\gamma$-secretase substrate selection, processing and toxicity. Prog Neurobiol 98:166-175

Baulac S, LaVoie MJ, Kimberly WT, Strahle J, Wolfe MS, Selkoe DJ, Xia W (2003) Functional gamma-secretase complex assembly in Golgi/trans-Golgi network: interactions among presenilin, nicastrin, Aph1, Pen-2, and gamma-secretase substrates. Neurobiol Dis 14:194-204

Beckett C, Nalivaeva NN, Belyaev ND, Turner AJ (2012) Nuclear signaling by membrane protein intracellular domains: the AICD enigma. Cell Signal 24:402-409

Bezprozvanny I, Mattson MP (2008) Neuronal calcium mishandling and the pathogenesis of Alzheimer's disease. Trends Neurosci 9:454-463

Bland CE, Kimberly P, Rand MD (2003) Notch induced proteolysis and nuclear localization of the Delta ligand. J Biol Chem 278:13607-13610

Bray SJ (2006) Notch signalling: a simple pathway becomes complex. Nat Rev Mol Cell Biol 7:678-689

Brou C (2009) Intracellular trafficking of Notch receptors and ligands. Exp Cell Res 315:1549-1555

Brown MS, Ye J, Rawson RB, Goldstein JL (2000) Regulated intramembrane proteolysis: a control mechanism conserved from bacteria to humans. Cell 100:391-398

Buchanan SM, Schalm SS, Maniatis T (2010) Proteolytic processing of protocadherin proteins requires endocytosis. Proc Natl Acad Sci USA 107:17774-17779

Buxbaum JD, Choi EK, Luo Y, Lilliehook C, Crowley AC et al (1998) Calsenilin: a calcium-binding protein that interacts with the presenilins and regulates the levels of a presenilin fragment. Nat Med 4:1177-1181

Ceresa BP (2006) Regulation of EGFR endocytic trafficking by rab proteins. Histol Histopathol 21:987-993

Chen AC, Guo LY, Ostaszewski BL, Selkoe DJ, LaVoie MJ (2010) Aph-1 associates directly with full-length and C-terminal fragments of $\gamma$-secretase substrates. J Biol Chem 285:11378-11391

Chen F, Hasegawa H, Schmitt-Ulms G et al (2006) TMP21 is a presenilin complex component that modulates gamma-secretase but not epsilon-secretase activity. Nature 440:1208-1212

Cheung KH, Shineman D, Müller M, Cárdenas C, Mei L, Yang J, Tomita T, Iwatsubo T, Lee VM, Foskett JK (2008) Mechanism of $\mathrm{Ca}^{2+}$ disruption in Alzheimer's disease by presenilin regulation of InsP3 receptor channel gating. Neuron 58:871-883

Cheung KH, Mei L, Mak DO, Hayashi I, Iwatsubo T, Kang DE, Foskett JK (2010) Gain-of-function enhancement of IP3 receptor modal gating by familial Alzheimer's disease-linked presenilin mutants in human cells and mouse neurons. Sci Signal 114:ra22

Citron M, Westaway D, Xia W, Carlson G, Diehl T et al (1997) Mutant presenilins of Alzheimer's disease increase production of 42residue amyloid beta-protein in both transfected cells and transgenic mice. Nat Med 3:67-72

Coen K, Flannagan RS, Baron S, Carraro-Lacroix LR, Wang D, Vermeire W, Michiels C, Munck S, Baert V, Sugita S, Wuytack F,
Hiesinger PR, Grinstein S, Annaert W (2012) Lysosomal calcium homeostasis defects, not proton pump defects, cause endo-lysosomal dysfunction in PSEN-deficient cells. J Cell Biol 198:23-35

Cowburn RF, Popescu BO, Ankarcrona M, Dehvari N, CedazoMinguez A (2007) Presenilin-mediated signal transduction. Physiol Behav 92:93-97

Crump CJ, Johnson DS, Li YM (2011) Target of $\gamma$-secretase modulators, presenilin marks the spot. EMBO J 30:4696-4698

Crystal AS, Morais VA, Pierson TC, Pijak DS, Carlin D, Lee VM, Doms RW (2003) Membrane topology of gamma-secretase component PEN-2. J Biol Chem 278:20117-20123

De Strooper B, Annaert W, Cupers P, Saftig P, Craessaerts K, Mumm JS, Schroeter EH, Schrijvers V, Wolfe MS, Ray WJ, Goate A, Kopan R (1999) A presenilin-1-dependent gamma-secretase-like protease mediates release of Notch intracellular domain. Nature 398:518-522

De Strooper B, Annaert W (2010) Novel research horizons for presenilins and $\gamma$-secretases in cell biology and disease. Annu Rev Cell Dev Biol 26:235-260

Del Amo FF, Smith DE, Swiatek PJ, Gendron-Maguire M, Greenspan RJ, McMahon AP, Gridley T (1992) Expression pattern of Motch, a mouse homolog of Drosophila Notch, suggests an important role in early postimplantation mouse development. Development 115:737-744

Dries DR, Yu G (2008) Assembly, maturation, and trafficking of the gamma-secretase complex in Alzheimer's disease. Curr Alzheimer Res 5:132-146

Dries DR, Shah S, Han YH, Yu C, Yu S, Shearman MS, Yu G (2009) Glu-333 of nicastrin directly participates in $\gamma$-secretase activity. J Biol Chem 284:29714-29724

Dumanchin C, Czech C, Campion D, Cuif MH, Poyot T, Martin C, Charbonnier F, Goud B, Pradier L, Frebourg T (1999) Presenilins interact with Rab11, a small GTPase involved in the regulation of vesicular transport. Hum Mol Genet 8:1263-1269

Esler WP, Kimberly WT, Ostaszewski BL, Ye W, Diehl TS, Selkoe DJ, Wolfe MS (2002) Activity-dependent isolation of the presenilin$\gamma$-secretase complex reveals nicastrin and a $\gamma$ substrate. Proc Natl Acad Sci USA 99:2720-2725

Esselens C, Oorschot V, Baert V, Raemaekers T, Spittaels K et al (2004) Presenilin-1 mediates the turnover of telencephalin in hippocampal neurons via an autophagic degradative pathway. J Cell Biol 166:1041-1054

Etcheberrigaray R, Hirashima N, Nee L, Prince J, Govoni S, Racchi M, Tanzi RE, Alkon DL (1998) Calcium responses in fibroblasts from asymptomatic members of Alzheimer' s disease families. Neurobiol Dis 5:37-45

Farfara D, Trudler D, Segev-Amzaleg N, Galron R, Stein R, Frenkel D (2011) $\gamma$-Secretase component presenilin is important for microglia $\beta$-amyloid clearance. Ann Neurol 69:170-180

Fassler M, Li X, Kaether C (2011) Polar transmembrane-based amino acids in presenilin 1 are involved in endoplasmic reticulum localization, Pen 2 protein binding, and $\gamma$-secretase complex stabilization. J Biol Chem 286:38390-38396

Fassler M, Zocher M, Klare S, de la Fuente AG, Scheuermann J, Capell A, Haass C, Valkova C, Veerappan A, Schneider D, Kaether C (2010) Masking of transmembrane-based retention signals controls ER export of gamma-secretase. Traffic 11:250-258

Feldman RG, Chandler KA, Levy LL, Gaser GH (1963) Familial Alzheimer's disease. Neurology 13:811-824

Fortini ME (2002) Gamma-secretase-mediated proteolysis in cellsurface-receptor signalling. Nat Rev Mol Cell Biol 3:673-684

Fraering PC, LaVoie MJ, Ye W, Ostaszewski BL, Kimberly WT, Selkoe DJ, Wolfe MS (2004) Detergent-dependent dissociation of active c-secretase reveals an interaction between Pen-2 and PS1-NTF and offers a model for subunit organization within the complex. Biochemistry 43:323-333 
Frånberg J, Svensson WB, Karlström H, Frykman S (2011) Minor contribution of presenilin 2 for $\gamma$-secretase activity in mouse embryonic fibroblasts and adult mouse brain. Biochem Biophys Res Commun 404:564-568

Francis R, McGrath G, Zhang J, Ruddy DA, Sym M et al (2002) Aph-1 and pen- 2 are required for Notch pathway signaling, gammasecretase cleavage of betaAPP, and presenilin protein accumulation. Dev Cell 3:85-97

Frykman S, Hur JY, Frånberg J, Aoki M, Winblad B, Nahalkova J, Behbahani H, Tjernberg LO (2010) Synaptic and endosomal localization of active gamma-secretase in rat brain. PLoS One 5: e8948

Fukumori A, Okochi M, Tagami S, Jiang J, Itoh N, Nakayama T, Yanagida K, Ishizuka-Katsura Y, Morihara T, Kamino K, Tanaka T, Kudo T, Tanii H, Ikuta A, Haass C, Takeda M (2006) Presenilin-dependent gamma-secretase on plasma membrane and endosomes is functionally distinct. Biochemistry 45:4907-4914

Fürthauer M, González-Gaitán M (2009) Endocytic regulation of Notch signalling during development. Traffic 10:792-802

Futai E, Yagishita S, Ishiura S (2009) Nicastrin is dispensable for gamma-secretase protease activity in the presence of specific presenilin mutations. J Biol Chem 284:13013-13022

García-Pérez C, Hajnóczky G, Csordás G (2008) Physical coupling supports the local $\mathrm{Ca}^{2+}$ transfer between sarcoplasmic reticulum subdomains and the mitochondria in heart muscle. J Biol Chem 283:32771-32780

Geldner N, Robatzek S (2008) Plant receptors go endosomal: a moving view on signal transduction. Plant Physiol 147:1565-1574

Goutte C, Tsunozaki M, Hale VA, Priess JR (2002) APH-1 is a multipass membrane protein essential for the Notch signaling pathway in Caenorhabditis elegans embryos. Proc Natl Acad Sci USA 99:775-779

Grant BD, Donaldson JG (2009) Pathways and mechanisms of endocytic recycling. Nat Rev Mol Cell Biol 10:597-608

Green KN, Demuro A, Akbari Y, Hitt BD, Smith IF, Parker I, LaFerla FM (2008) SERCA pump activity is physiologically regulated by presenilin and regulates amyloid $\beta$ production. J Gen Physiol 132:1107-1116

Gu Y, Chen F, Sanjo N, Kawarai T, Hasegawa H et al (2003) APH-1 interacts with mature and immature forms of presenilins and nicastrin and may play a role in maturation of presenilin-nicastrin complexes. J Biol Chem 278:7374-7380

Guo Y, Zhang SX, Sokol N, Cooley L, Boulianne GL (2000) Physical and genetic interaction of filamin with presenilin in Drosophila. $\mathrm{J}$ Cell Sci 19:3499-3508

Hayashi T, Rizzuto R, Hajnoczky G, Su TP (2009) MAM: more than just a housekeeper. Trends Cell Biol 19:81-88

$\mathrm{He} \mathrm{G}$, Luo W, Li P et al (2010) Gamma-secretase activating protein is a therapeutic target for Alzheimer's disease. Nature 467:95-98

He G, Qing H, Tong Y, Cai F, Ishiura S, Song W (2007) Degradation of nicastrin involves both proteasome and lysosome. J Neurochem 101:982-992

Hemming ML, Elias JE, Gygi SP, Selkoe DJ (2008) Proteomic profiling of $\gamma$-secretase substrates and mapping of substrate requirements. PLoS Biol 6:e257

Herreman A, Hartmann D, Annaert W, Saftig P, Craessaerts K et al (1999) Presenilin 2 deficiency causes a mild pulmonary phenotype and no changes in amyloid precursor protein processing but enhances the embryonic lethal phenotype of presenilin 1 deficiency. Proc Natl Acad Sci USA 96:11872-11877

Hirashima N, Etcheberrigaray R, Bergamaschi S, Racchi M, Battaini F, Binetti G, Govoni S, Alkon DL (1996) Calcium responses in human fibroblasts: a diagnostic molecular profile for Alzheimer' s disease. Neurobiol Aging 17:549-555

Ho A, Shen J (2011) Presenilins in synaptic function and disease. Trends Mol Med 17:617-624
Hoe HS, Rebeck GW (2005) Regulation of ApoE receptor proteolysis by ligand binding. Brain Res Mol Brain Res 137:31-39

Ikeuchi T, Sisodia SS (2003) The Notch ligands, Delta1 and Jagged2, are substrates for presenilin-dependent "gamma-secretase" cleavage. J Biol Chem 278:7751-7754

Irani NG, Russinova E (2009) Receptor endocytosis and signaling in plants. Curr Opin Plant Biol 12:653-659

Ito E, Oka K, Etcheberrigaray R, Nelson TJ, McPhie DL, Tofel-Grehl $\mathrm{B}$, Gibson GE, Alkon DL (1994) Internal $\mathrm{Ca}^{2+}$ mobilization is altered in fibroblasts from patients with Alzheimer disease. Proc Natl Acad Sci USA 91:534-538

Jing J, Prekeris R (2009) Polarized endocytic transport: the roles of Rab11 and Rab11-FIPs in regulating cell polarity. Histol Histopathol 24:1171-1180

Jutras I, Laplante A, Boulais J, Brunet S, Thinakaran G, Desjardins M (2005) Gamma-secretase is a functional component of phagosomes. J Biol Chem 280:36310-36317

Kaether C, Capell A, Edbauer D, Winkler E, Novak B, Steiner H, Haass C (2004) The presenilin C-terminus is required for ERretention, nicastrin-binding and gamma-secretase activity. EMBO J 23:4738-4748

Kaether C, Haass C, Steiner H (2006a) Assembly, trafficking and function of gamma-secretase. Neurodegener Dis 3:275-283

Kaether C, Schmitt S, Willem M, Haass C (2006b) Amyloid precursor protein and Notch intracellular domains are generated after transport of their precursors to the cell surface. Traffic 7:408-415

Kaether C, Scheuermann J, Fassler M, Zilow S, Shirotani K, Valkova C, Novak B, Kacmar S, Steiner H, Haass C (2007) Endoplasmic reticulum retention of the gamma-secretase complex component Pen2 by Rer1. EMBO Rep 8:743-748

Kasuga K, Kaneko H, Nishizawa M, Onodera O, Ikeuchi T (2007) Generation of intracellular domain of insulin receptor tyrosine kinase by gamma-secretase. Biochem Biophys Res Commun 360:90-96

Kim DY, Ingano LA, Kovacs DM (2002) Nectin-1alpha, an immunoglobulin-like receptor involved in the formation of synapses, is a substrate for presenilin/gammasecretase-like cleavage. J Biol Chem 277:49976-49981

Kim J, Chang A, Dudak A, Federoff HJ, Lim ST (2011) Characterization of nectin processing mediated by presenilin-dependent gammasecretase. J Neurochem 119:945-956

Kim J, Schekman R (2004) The ins and outs of presenilin 1 membrane topology. Proc Natl Acad Sci USA 101:905-906

Kim SH, Sisodia SS (2005) Evidence that the "NF" motif in transmembrane domain 4 of presenilin 1 is critical for binding with PEN-2. J Biol Chem 280:41953-41966

Khandelwal A, Chandu D, Roe CM, Kopan R, Quatrano RS (2007) Moonlighting activity of presenilin in plants is independent of gamma-secretase and evolutionarily conserved. Proc Natl Acad Sci USA 104:13337-13342

Knobloch M, Mansuy IM (2008) Dendritic spine loss and synaptic alterations in Alzheimer's disease. Mol Neurobiol 37:73-82

Kopan R, Ilagan MX (2004) Gamma-secretase: proteasome of the membrane? Nat Rev Mol Cell Biol 5:499-504

Kornilova AY, Bihel F, Das C, Wolfe MS (2005) The initial substratebinding site of c-secretase is located on presenilin near the active site. Proc Natl Acad Sci USA 102:3230-3235

Kosicek M, Malnar M, Goate A, Hecimovic S (2010) Cholesterol accumulation in Niemann Pick type C (NPC) model cells causes a shift in APP localization to lipid rafts. Biochem Biophys Res Commun 393:404-409

Kume H, Kametani F (2006) A $\beta$ 11-40/42 production without $\gamma$ secretase $\varepsilon$-site cleavage. Biochem Biophys Res Commun 349:1356-1360

Lal M, Caplan M (2011) Regulated intramembrane proteolysis: signaling pathways and biological functions. Physiology (Bethesda) $26: 34-44$ 
Le Bras S, Loyer N, Le Borgne R (2011) The multiple facets of ubiquitination in the regulation of notch signaling pathway. Traffic 12:149-161

Lee HJ, Jung KM, Huang YZ, Bennett LB, Lee JS, Mei L, Kim TW (2002) Presenilin-dependent gamma-secretase-like intramembrane cleavage of ErbB4. J Biol Chem 277:6318-6323

Lee JH, Yu WH, Kumar A, Lee S, Mohan PS et al (2010) Lysosomal proteolysis and autophagy require presenilin 1 and are disrupted by Alzheimer-related PS1 mutations. Cell 141:1146-1158

Lemberg MK (2011) Intramembrane proteolysis in regulated protein trafficking. Traffic 12:1109-1118

Levitan D, Greenwald I (1995) Facilitation of lin-12-mediated signalling by sel-12, a Caenorhabditis elegans S182 Alzheimer's disease gene. Nature 377:351-354

Levitan D, Yu G, St George Hyslop P, Goutte C (2001) APH-2/nicastrin functions in LIN-12/Notch signaling in the Caenorhabditis elegans somatic gonad. Dev Biol 240:654-661

LeVoie MJ, Selkoe DJ (2003) The Notch ligands, Jagged and Delta, are sequentially processed by alpha-secretase and presenilin/gammasecretase and release signaling fragments. J Biol Chem 278:3442734437

Li X, Greenwald I (1996) Membrane topology of the C. elegans SEL12 presenilin. Neuron 17:1015-1021

Li X, Dang S, Yan C, Gong X, Wang J, Shi Y (2013) Structure of a presenilin family intramembrane aspartate protease. Nature 493: $56-61$

Lichtenthaler SF, Haass C, Steiner H (2011) Regulated intramembrane proteolysis - lessons from amyloid precursor protein processing. $\mathrm{J}$ Neurochem 117:779-796

Ma G, Li T, Price DL, Wong PC (2005) APH-1a is the principal mammalian APH-1 isoform present in gamma-secretase complexes during embryonic development. J Neurosci 25:192-198

Mao G, Cui MZ, Li T, Jin Y, Xu X (2012) Pen-2 is dispensable for endoproteolysis of presenilin 1, and nicastrin-Aph subcomplex is important for both $\gamma$-secretase assembly and substrate recruitment. J Neurochem 123:837-844

Marambaud P, Shioi J, Serban G, Georgakopoulos A, Sarner S et al (2002) A presenilin-1/gamma-secretase cleavage releases the Ecadherin intracellular domain and regulates disassembly of adherens junctions. EMBO J 21:1948-1956

May P, Bock HH, Nimpf J, Herz J (2003) Differential glycosylation regulates processing of lipoprotein receptors by gamma-secretase. J Biol Chem 278:37386-37392

McCarthy JV, Twomey C, Wujek P (2009) Presenilin-dependent regulated intramembrane proteolysis and $\gamma$-secretase activity. Cell Mol Life Sci 66:1534-1555

McMains VC, Myre M, Kreppel L, Kimmel AR (2010) Dictyostelium possesses highly diverged presenilin $/ \gamma$-secretase that regulates growth and cell-fate specification and can accurately process human APP: a system for functional studies of the presenilin $/ \gamma$ secretase complex. Dis Model Mech 3:581-594

Morishita H, Yagi T (2007) Protocadherin family: diversity, structure, and function. Curr Opin Cell Biol 19:584-92

Müller M, Cardenas C, Mei L, Cheung FJK (2011a) Constitutive cAMP response element binding protein (CREB) activation by Alzheimer's disease presenilin-driven inositol trisphosphate receptor (InsP3R) $\mathrm{Ca}^{2+}$ signaling. Proc Natl Acad Sci USA 32:13293-13298

Müller M, Cheung KH, Foskett JK (2011b) Enhanced ROS generation mediated by Alzheimer's disease presenilin regulation of InsP3R $\mathrm{Ca}^{2+}$ signaling. Antioxid Redox Signal 7:1225-1235

Nahalkova J, Volkmann I, Aoki M, Winblad B, Bogdanovic N, Tjernberg LO, Behbahani H (2010) CD147, a gamma-secretase associated protein is upregulated in Alzheimer's disease brain and its cellular trafficking is affected by presenilin-2. Neurochem Int 56:67-76

Nakayama K, Nagase H, Koh CS, Ohkawara T (2011) $\gamma$-Secretaseregulated mechanisms similar to Notch signaling may play a role in signaling events, including APP signaling, which leads to Alzheimer's disease. Cell Mol Neurobiol 31:887-900

Neely KM, Green KN, LaFerla FM (2011) Presenilin is necessary for efficient proteolysis through the autophagy-lysosome system in a $\gamma$-secretase-independent manner. J Neurosci 31:2781-2791

Neely Kayala KM, Dickinson GD, Minassian A, Walls KC, Green KN, Laferla FM (2012) Presenilin-null cells have altered two-pore calcium channel expression and lysosomal calcium: implications for lysosomal function. Brain Res 1489:8-16

Nelson O, Supnet C, Tolia A, Horré K, De Strooper B, Bezprozvanny I (2011) Mutagenesis mapping of the presenilin 1 calcium leak conductance pore. J Biol Chem 286:22339-22347

Ni CY, Murphy MP, Golde TE, Carpenter G (2001) gamma-Secretase cleavage and nuclear localization of ErbB-4 receptor tyrosine kinase. Science 294:2179-2181

Nichols JT, Miyamoto A, Weinmaster G (2007) Notch signaling constantly on the move. Traffic 8:959-969

Nixon RA, Yang DS (2011) Autophagy failure in Alzheimer's diseaselocating the primary defect. Neurobiol Dis 43:38-45

Oh HG, Chun YS, Kim Y, Youn SH, Shin S, Park MK, Kim TW, Chung S (2012) Modulation of transient receptor potential melastatin related 7 (TRPM7) channel by presenilins. Dev Neurobiol 72:865-877

Ohta K, Mizuno A, Ueda M, Li S, Suzuki Y, Hida Y, Hayakawa-Yano Y, Itoh M, Ohta E, Kobori M, Nakagawa T (2010) Autophagy impairment stimulates PS1 expression and gamma-secretase activity. Autophagy 6:345-352

Osenkowski P, Li H, Ye W, Li D, Aeschbach L, Fraering PC, Wolfe MS, Selkoe DJ, Li H (2009) Cryoelectron microscopy structure of purified gamma-secretase at $12 \AA$ resolution. J Mol Biol 385:642-652

Pack-Chung E, Meyers MB, Pettingell WP, Moir RD, Brownawell AM et al (2000) Presenilin 2 interacts with sorcin, a modulator of the ryanodine receptor. J Biol Chem 275:14440-14445

Pardossi-Piquard R, Yang SP, Kanemoto S, Gu Y, Chen F et al (2009) APH1 polar transmembrane residues regulate the assembly and activity of presenilin complexes. J Biol Chem 284:16298-16307

Parks AL, Curtis D (2007) Presenilin diversifies its portfolio. Trends Genet 23:140-150

Pasternak SH, Bagshaw RD, Guiral M, Zhang S, Ackerley CA, Pak BJ, Callahan JW, Mahuran DJ (2003) Presenilin-1, nicastrin, amyloid precursor protein, and gamma-secretase activity are colocalized in the lysosomal membrane. J Biol Chem 278:2668726694

Placanica L, Chien JW, Li YM (2010) Characterization of an atypical gamma-secretase complex from hematopoietic origin. Biochemistry 13:2796-2804

Ponting CP, Hutton M, Nyborg A, Baker M, Jansen K, Golde TE (2002) Identification of a novel family of presenilin homologues. Hum Mol Genet 11:1037-1044

Pratt KG, Zhu P, Watari H, Cook DG, Sullivan JM (2011) A novel role for $\gamma$-secretase: selective regulation of spontaneous neurotransmitter releasefrom hippocampal neurons. J Neurosci 3:899-906

Quintero-Monzon O, Martin MM, Fernandez MA, Cappello CA, Krzysiak AJ, Osenkowski P, Wolfe MS (2011) Dissociation between the processivity and total activity of $\gamma$-secretase: implications for the mechanism of Alzheimer's disease causing presenilin mutations. Biochemistry 42:9023-9035

Rabinowitz JD, White E (2010) Autophagy and metabolism. Science 330:1344-1348

Rajendran L, Honsho M, Zahn TR, Keller P, Geiger KD, Verkade P, Simons K (2006) Alzheimer's disease beta-amyloid peptides are released in association with exosomes. Proc Natl Acad Sci USA 103:11172-11177

Réchards M, Xia W, Oorschot VM, Selkoe DJ, Klumperman J (2003) Presenilin-1 exists in both pre- and post-Golgi compartments and recycles via COPI-coated membranes. Traffic 4:553-565 
Ren Z, Schenk D, Basi GS, Shapiro IP (2007) Amyloid $\beta$-protein precursor juxtamembrane domain regulates specificity of $\gamma$ secretase-dependent cleavages. J Biol Chem 282:35350-35360

Renzi F, Zhang X, Rice WJ, Torres-Arancivia C, Gomez-Llorente Y et al (2011) Structure of gamma-secretase and its trimeric preactivation intermediate by single-particle electron microscopy. J Biol Chem 286:21440-21449

Repetto E, Yoon IS, Zheng H, Kang DE (2007) Presenilin 1 regulates epidermal growth factor receptor turnover and signaling in the endosomal-lysosomal pathway. J Biol Chem 282:31504-31516

Restituito S, Khatri L, Ninan I, Mathews PM, Liu X, Weinberg RJ, Ziff EB (2011) Synaptic autoregulation by metalloproteases and $\gamma$ secretase. J Neurosci 31:12083-12093

Rogaev EI, Sherrington R, Rogaeva EA et al (1995) Familial Alzheimer's disease in kindreds with missense mutations in a gene on chromosome 1 related to the Alzheimer's disease type 3 gene. Nature 376:775-778

Rybalchenko V, Hwang SY, Rybalchenko N, Koulen P (2008) The cytosolic N-terminus of presenilin-1 potentiates mouse ryanodine receptor single channel activity. Int J Biochem Cell Biol 40:84-97

Sadowski L, Pilecka I, Miączyńska M (2009) Signaling from endosomes: location makes a difference. Exp Cell Res 315:1601-1609

Šamaj J, Read ND, Volkmann D, Menzel D, Baluška F (2005) The endocytic network in plants. Trends Cell Biol 15:425-433

Sannerud R, Annaert W (2009) Trafficking, a key player in regulated intramembrane proteolysis. Sem Cell Dev Biol 20:183-190

Sato C, Morohashi Y, Tomita T, Iwatsubo T (2006) Structure of the catalytic pore of $\gamma$-secretase probed by the accessibility of substituted cysteines. J Neurosci 26:12081-12088

Sato C, Takagi S, Tomita T, Iwatsubo T (2008) The C-terminal PAL motif and transmembrane domain 9 of presenilin 1 are involved in the formation of the catalytic pore of the $\gamma$-secretase. J Neurosci 28:6264-6271

Saura CA, Servian-Morilla E, Scholi FG (2011) Presenilin $/ \gamma$-secretase regulates neurexin processing at synapses. PLoS One 4:e19430

Selkoe DJ, Wolfe MS (2007) Presenilin: running with scissors in the membrane. Cell 131:215-221

Sethi N, Kang Y (2011) Notch signalling in cancer progression and bone metastasis. Br J Cancer 105:1805-1810

Shah S, Lee SF, Tabuchi K, Hao YH, Yu C, Laplant Q, Ball H, Dann CE 3rd, Sudhof T, Yu G (2005) Nicastrin functions as a $\gamma$ secretase-substrate receptor. Cell 122:435-447

Sherrington R, Rogaev EI, Liang Y, Rogaeva EA, Levesque G et al (1995) Cloning of a gene bearing missense mutations in earlyonset familial Alzheimer's disease. Nature 375:754-760

Shilling D, Mak DO, Kang DE, Foskett JK (2012) Lack of evidence for presenilins as endoplasmic reticulum $\mathrm{Ca}^{2+}$ leak channels. $\mathrm{J}$ Biol Chem 287:10933-10944

Shilo BZ, Schejter ED (2011) Regulation of developmental intercellular signalling by intracellular trafficking. EMBO J 30:3516-3526

Shinozaki K, Maruyama K, Kume H, Tomita T, Saido TC, Iwatsubo T et al (1998) The presenilin 2 loop domain interacts with the mucalpain C-terminal region. Int J Mol Med 1:797-799

Shirotani K, Edbauer D, Capell A, Schmitz J, Steiner H, Haass C (2003) Gamma-secretase activity is associated with a conformational change of nicastrin. J Biol Chem 278:16474-16477

Six E, Ndiaye D, Laabi Y, Brou C, Gupta-Rossi N, Israel A, Logeat F (2003) The Notch ligand Delta1 is sequentially cleaved by an ADAM protease and gammasecretase. Proc Natl Acad Sci USA 100:7638-7643

Smith SK, Anderson HA, Yu G, Robertson AG, Allen SJ et al (2000) Identification of syntaxin $1 \mathrm{~A}$ as a novel binding protein for presenilin-1. Brain Res Mol Brain Res 78:100-107

Smolarkiewicz M (2012) Structural and functional analysis of the subunits of gamma-secretase complex in Arabidopsis thaliana. $\mathrm{PhD}$ thesis. Adam Mickiewicz University, Poznań
Sobhanifar S, Schneider B, Löhr F, Gottstein D, Ikeya T et al (2010) Structural investigation of the C-terminal catalytic fragment of presenilin 1. Proc Natl Acad Sci USA 107:9644-9649

Sorensen EB, Conner SD (2010) $\gamma$-Secretase-dependent cleavage initiates notch signaling from the plasma membrane. Traffic 11:1234-1245

Sorkin A, von Zastrow M (2009) Endocytosis and signalling: intertwining molecular networks. Nat Rev Mol Cell Biol 10:609-622

Spasic D, Annaert W (2008) Building gamma-secretase: the bits and pieces. J Cell Sci 121:413-420

Spasic D, Tolia A, Dillen K, Baert V, De Strooper B, Vrijens S, Annaert W (2006) Presenilin-1 maintains a nine-transmembrane topology throughout the secretory pathway. J Biol Chem 281:26569-26577

Spasic D, Raemaekers T, Dillen K, Declerck I, Baert V, Serneels L, Füllekrug J, Annaert W (2007) Rer1p competes with APH-1 for binding to nicastrin and regulates gamma-secretase complex assembly in the early secretory pathway. J Cell Biol 176:629-640

Stabler SM, Ostrowski LL, Janicki SM, Monteiro MJ (1999) A myristoylated calcium-binding protein that preferentially interacts with the Alzheimer's disease presenilin 2 protein. J Cell Biol 145:1277-1292

Steiner H, Winkler E, Haass C (2008) Chemical cross-linking provides a model of the $\gamma$-secretase complex subunit architecture and evidence for close proximity of the C-terminal fragment of presenilin with APH-1. J Biol Chem 283:34677-34686

St George-Hyslop P, Fraser PE (2012) Assembly of presenilin $\gamma-/ \varepsilon$ secretase complex. J Neurochem 120:84-88

Suga K, Saito A, Tomiyama T, Mori H, Akagawa K (2005) Syntaxin 5 interacts specifically with presenilin holoproteins and affects processing of $\beta$ APP in neuronal cells. J Neurochem 94:425-439

Supnet C, Bezprozvanny I (2011) Presenilins function in ER calcium leak and Alzheimer's disease pathogenesis. Cell Calcium 50:303309

Takagi S, Tominaga A, Sato C, Tomita T, Iwatsubo T (2010) Participation of transmembrane domain 1 of presenilin 1 in the catalytic pore structure of the c-secretase. J Neurosci 30:15943-15950

Tamboli IY, Prager K, Thal DR, Thelen KM, Dewachter I et al (2008) Loss of gamma-secretase function impairs endocytosis of lipoprotein particles and membrane cholesterol homeostasis. J Neurosci 28:12097-12106

Taub N, Teis D, Ebner HL, Hess MW, Huber LA (2007) Late endosomal traffic of the epidermal growth factor receptor ensures spatial and temporal fidelity of mitogen-activated protein kinase signaling. Mol Biol Cell 18:4698-4710

Tien AC, Rajan A, Bellen HJ (2009) A Notch updated. J Cell Biol 184:621-629

Tolia A, Chavez-Gutierrez L, De Strooper B (2006) Contribution of presenilin transmembrane domains 6 and 7 to a water-containing cavity in the $\gamma$-secretase complex. J Biol Chem 281:27633-27642

Tolia A, Horre K, De Strooper B (2008) Transmembrane domain 9 of presenilin determines the dynamic conformation of the catalytic site of c-secretase. J Biol Chem 283:19793-19803

Torres-Arancivia C, Ross CM, Chavez J, Assur Z, Dolios G, Mancia F, Ubarretxena-Belandia I (2010) Identification of an archaeal presenilin-like intramembrane protease. PLoS One 5:e13072

Tu H, Nelson O, Bezprozvanny A, Wang Z, Lee SF, Hao YH, Serneels L, De Strooper B, Yu G, Bezprozvanny I (2006) Presenilins form $\mathrm{ER} \mathrm{Ca}^{2+}$ leak channels, a function disrupted by familial Alzheimer's disease-linked mutations. Cell 126:981-993

Underhill DM, Ozinsky A (2002) Phagocytosis of microbes: complexity in action. Annu Rev Immunol 20:825-852

Urano Y, Hayashi I, Isoo N, Reid PC, Shibasaki Y, Noguchi N, Tomita T, Iwatsubo T, Hamakubo T, Kodama T (2005) Association of active $\gamma$-secretase complex with lipid rafts. J Lipid Res 46:904-912 
Urban S, Lee JR, Freeman M (2001) Drosophila rhomboid-1 defines a family of putative intramembrane serine proteases. Cell 107:173182

Vaccari T, Lu H, Kanwar R, Fortini ME, Bilder D (2008) Endosomal entry regulates Notch receptor activation in Drosophila melanogaster. J Cell Biol 180:755-762

van Tetering G, Vooijs M (2011) Proteolytic cleavage of Notch: "HIT and RUN". Curr Mol Med 11:255-269

Watanabe N, Tomita T, Sato C, Kitamura T, Morohashi Y, Iwatsubo T (2005) Pen-2 is incorporated into the c-secretase complex through binding to transmembrane domain 4 of presenilin 1. J Biol Chem 280:41967-41975

Weidemann A, Eggert S, Reinhard FB, Vogel M, Paliga K, Baier G, Masters CL, Beyreuther K, Evin G (2002) A novel $\varepsilon$-cleavage within the transmembrane domain of the Alzheimer amyloid precursor protein demonstrates homology with Notch processing. Biochemistry 41:2825-2835

Weyand NJ, Calton CM, Higashi DL, Kanack KJ, Magdalene S (2010) Presenilin/gamma-secretase cleaves CD46 in response to Neisseria infection. J Immunol 184:694-701

Wilson CA, Murphy DD, Giasson BI, Zhang B, Trojanowski JQ, Lee VM (2004) Degradative organelles containing mislocalized $\alpha$ and $\beta$-synuclein proliferate in Presenilin-1 null neurons. J Cell Biol 165:335-346

Wolfe MS (2009) gamma-secretase in biology and medicine. Semin Cell Dev Biol 20:219-224

Wolfe MS (2012) $\gamma$-Secretase inhibitors and modulators for Alzheimer's disease. J Neurochem 120(Suppl 1):89-98

Yonemura Y, Futai E, Yagishita S, Suo S, Tomita T, Iwatsubo T, Ishiura $\mathrm{S}$ (2011) Comparison of presenilin 1 and presenilin $2 \gamma$-secretase activities using a yeast reconstitution system. J Biol Chem 286:44569-44575

Yu G, Nishimura M, Arawaka S, Levitan D, Zhang L et al (2000) Nicastrin modulates presenilin-mediated notch/glp-1 signal transduction and $\beta A P P$ processing. Nature 407:48-54

Yu C, Kim SH, Ikeuchi T, Xu H, Gasparini L, Wang R, Sisodia SS (2001) Characterization of a presenilin-mediated APP carboxyl terminal fragment CTFc: evidence for distinct mechanisms involved in c-secretase processing of the APP and Notch1 transmembrane domains. J Biol Chem 276:43756-43760

Zampese E, Fasolato C, Kipanyula MJ, Bortolozzi M, Pozzan T (2011) Presenilin 2 modulates endoplasmic reticulum (ER)-mitochondria interactions and $\mathrm{Ca}^{2+}$ cross-talk. Proc Natl Acad Sci USA 108:2777-2782

Zhang C, Wu B, Beglopoulos V, Wines-Samuelson M, Zhang D, Dragatsis I, Südhof TC, Shen J (2009) Presenilins are essential for regulating neurotransmitter release. Nature 460:632-636

Zhang H, Sun S, Herreman A, De Strooper B, Bezprozvanny I (2010) Role of presenilins in neuronal calcium homeostasis. J Neurosci 30:8566-8580

Zhang M, Haapasalo A, Kim DY, Ingano LA, Pettingell WH, Kovacs DM (2006) Presenilin/gamma-secretase activity regulates protein clearance from the endocytic recycling compartment. FASEB J 20:1176-1178

Zhang W, Han SW, McKeel DW, Goate A, Wu JY (1998) Interaction of presenilins with the filamin family of actin-binding proteins. $\mathrm{J}$ Neurosci 8:914-922

Zhang X, Garbett K, Veeraraghavalu K, Wilburn B, Gilmore R, Mirnics K, Sisodia SS (2012) A role for presenilins in autophagy revisited: normal acidification of lysosomes in cells lacking PSEN1 and PSEN2. J Neurosci 32:8633-8648

Zhao G, Cui MZ, Mao G, Dong Y, Tan J, Sun L, Xu X (2005) gammacleavage is dependent on zeta-cleavage during the proteolytic processing of amyloid precursor protein within its transmembrane domain. J Biol Chem 280:37689-37697

Zhao G, Liu Z, Ilagan MX, Kopan R (2010) $\gamma$-Secretase composed of PS1/Pen2/Aph1a can cleave notch and amyloid precursor protein in the absence of nicastrin. J Neurosci 30:1648-1656

Zhou S, Zhou H, Walian PJ, Jap BK (2005) CD147 is a regulatory subunit of the gamma-secretase complex in Alzheimer's disease amyloid beta-peptide production. Proc Natl Acad Sci USA 102:7499-7504

Zou K, Hosono T, Nakamura T, Shiraishi H, Maeda T et al (2008) Novel role of presenilins in maturation and transport of integrin beta 1 . Biochemistry 47:3370-3378

Zwang Y, Yarden Y (2009) Systems biology of growth factor-induced receptor endocytosis. Traffic 10:349-363 